\title{
El CUIDAdo de la ESTANCIA HUMANA
}

\section{Construir Habitar Pensar (Bauen Wohnen Denken) \\ Martin Heidegger [Edición bilingüe de A. Leyte y J. Adrián] \\ La Oficina Ediciones, 2015 \\ 88 págs. 18 euros}

$\mathrm{E}$

nfrentarse a una obra de Heidegger es en muchas ocasiones bucear entre sus palabras buscando lo que oculta o dicho de otra manera buscando lo que se omite más que lo que se expresa; hay que interpretar, des-velar los múltiples significados del lenguaje utilizado. Esto es especialmente relevante en este opúsculo, y no porque su oscuridad sea mayor que la de otras obras del autor sino por el análisis lingüístico tan minucioso que realiza para explorar las preguntas que se hace sobre cómo debe ser el construir para que satisfaga su único fin que es el habitar. De ahí, también los dos comentarios que siguen a la obra en esta edición bilingüe a cargo de Arturo Leyte y Jesús Adrián.

Aunque el texto se refiere a una realidad radicalmente distinta a la nuestra, sin embargo el marco teórico que cubre, puede ser pertinente en el

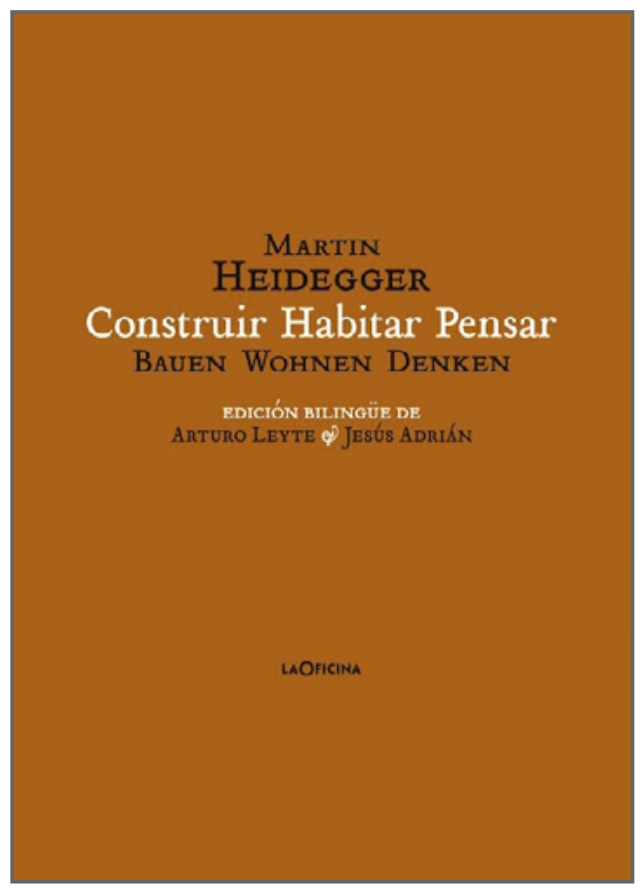

momento actual debido sobre todo al carácter abstracto de la propuesta.

Construir, Habitar, Pensar es la transcripción de una conferencia impartida por Martin Heidegger en el auditorio de la ciudad de Darmstadt en 1951 ante la preocupante situación de la falta de viviendas en ese momento en Alemania. A la conferencia asistieron técnicos, arquitectos, 
urbanistas, todos aquellos implicados y preocupados en la reconstrucción de las ciudades después de la devastación de la guerra.

Pero nos encontramos ante un texto que no pretende ser un tratado sobre arquitectura, el mismo Heidegger así nos lo indica nada más comenzar. Su objetivo está muy claro: pensar sobre el habitar y el construir; por tanto, va más allá de los aspectos técnicos o instrumentales de lo que sería el edificar o producir edificios. Partiendo del hecho de que el fin del construir es el habitar (ambas palabras traducen el mismo término del alemán antiguo: buan), trata de aclarar la esencia misma del habitar como lo que definirá el propio estar del ser humano sobre la Tierra. Y será este pensar en el fundamento, este carácter filosófico de su planteamiento, lo que le haga preguntarse por las condiciones del habitar desde el desamparo, desde el «desarraigo», nos dirá Heidegger, del existir humano. La precariedad del hombre viviendo en la tierra le lleva a construir su alojamiento buscando cierta permanencia para su continua inestabilidad. Sin duda, le interesan más a Heidegger las coordenadas que van definiendo el espacio vital de este ser enraizado en la tierra, su manera de vivir en el mundo que el propio hecho de cómo realizar concretamente cualquier tipo de construcción.

En un pormenorizado análisis etimológico, el texto nos va conduciendo a la naturaleza del habitar como lo propio de los seres humanos $\mathrm{y}$, por tanto, plantea una mirada en profundidad que habrá que tener siempre en cuenta cuando se construya cualquier tipo de edificación o vivienda. Nos recomienda escuchar lo que el lenguaje dice, y así va desplegando desde su origen todo un abanico de significados desde la palabra construir para llegar a la esencia última del término habitar que el propio lenguaje ha olvidando o ha dejando velada. «Ser un ser humano significa estar sobre la tierra como mortal o como ser que habita». Este concepto de habitar es más que una cualidad añadida, es «la forma en que nosotros, los humanos somos sobre la tierra». «El hombre es en la medida en que habita». Y así se van derivando una serie de conceptos que enriquecen el sentido del habitar desde sus primitivas raíces: vivir en proximidad, el permanecer que lleva a estar satisfechos y en paz, el habitar como proteger y cuidar, preservar y cultivar, con todos los matices que este último término arrastra (culti- 
var el campo, cuidar en el sentido latino de cultura, edificar...). Toda esta riqueza significativa no hace sino dotar de contenido al concepto de habitar al mismo tiempo que impregna de cierta belleza a este discurso sobre los humanos como seres que viven en la tierra y habitan en ella.

Para los heideggerianos confesos, esa colección de términos emparentados que van definiendo el sentido del ser, en este caso del existente humano como ser que habita, puede suponer un auténtico disfrute.

El habitar como el preservar de daños y tener cuidado significa permanecer y hacerlo sobre la tierra y bajo el cielo, pero no viviendo en un centro alrededor del cual giren las cosas, sino en un marco de relaciones: tierra, cielo, divinos y mortales. Estos elementos no se contraponen, conviven en una unidad originaria, es la simplicidad de la cuaternidad, nos dirá Heidegger, que dará vida al propio existir de los mortales en la relación entre ellos y con las cosas o lugares. Así el ser humano permanece en la cuaternidad junto a las cosas. Después del análisis detallado del cuádruple juego de elementos que forman el habitar, la propuesta de integración en la naturaleza para la construcción de espacios habitables resulta casi evidente.

Pero sorprende en el texto la elección del puente como ejemplo de obra construida; aparece casi como una metáfora, que al leerlo detenidamente se nos puede ir revelando como una definición del carácter transitorio del existir de los humanos, del carácter dinámico de la vida o también puede que se refiera simplemente y sin más a otro tipo de construcción vinculada al espacio que el hombre habita. El puente parece un símbolo que muestra la relación como una cualidad de lo existente que ya quedaba patente cuando hablaba de la cuaternidad, huyendo siempre de toda sustancialidad: el puente como camino entre, como tránsito hacia, desde... En cualquier caso, el detalle con el que se analizan las características de su construcción resulta un tanto desconcertante cuando al mismo tiempo observamos que el tema de cómo habitar ni está resuelto, ni parece importarle mucho a Heidegger. El porqué se plantea este modelo de obra, utilizando el puente en lugar de la vivienda para hablar de la relación del hombre con el espacio, y el lenguaje utilizado para referirse a él, es una de las dificultades en la 
lectura de este texto, en cuanto que abre paso a distintas vías de interpretación.

Sin embargo, sólo en escasas líneas se menciona un modelo de vivienda cuando se refiere a la casa rural de la Selva Negra en la ladera de una montaña de hacía dos siglos, que aunque cumpliendo perfectamente las funciones del habitar en su construcción y ligada a las necesidades naturales, parece constituir un punto de nostalgia por el pasado, por los tiempos predemocráticos, y resulta impracticable ya en esos momentos, como el mismo Heidegger reconoce. Lo que sí muestra con claridad este ejemplo de vivienda es el acercamiento y adaptación a la naturaleza, siempre defendido por el autor, frente a su distanciamiento del mundo de la técnica que ejerce su dominio y control sobre lo natural y sometido habitualmente a sus duras críticas.

Así pues en Construir, Habitar, Pensar no podemos encontrar criterios ni modelos que nos sirvan para las necesidades de nuestras complejas sociedades urbanas, ni por supuesto para sociedades cuya habitación ni siquiera se puede considerar humana debido a la pobreza o extrema pobreza en que viven millones de seres humanos, pero sí es válido como llamada de atención para repensar las relaciones con el medio físico y humano que debería constituir la base de todos los hogares en cualquier tipo de sociedad.

Por eso es importante pensar y preguntarnos por el habitar y construir, preguntas que nos llevan a evitar el desarraigo, propio de la existencia. Éste es uno de los motivos de la pertinencia de la lectura del presente texto —al que hacía mención al principio-, cómo el construir funda y organiza espacios si lo realizamos desde nuestra preocupación por el habitar como rasgo fundamental del existir. Por supuesto que hoy no padecemos, si hablamos de sociedades desarrolladas o tecnológicas, de la precariedad y ausencia de viviendas como en la época en que está dictada esta conferencia, pero es indudable que falta pensar o reflexionar sobre las condiciones del habitar para dotar de un carácter más humano a nuestros lugares; es la llamada a pensar el sentido del habitar en la tierra, lo que suscita verdadero interés en un texto como éste.

¿Puede conducirnos a algo más su lectura cuando sin duda necesi- 
tamos revisar las formas de convivir a través de nuestras ciudades en sociedades democráticas, y la visión de Heidegger está totalmente alejada de este modelo político y social? La respuesta es no, si lo que buscamos aquí son soluciones concretas a nuestra manera de construir, pero reflexionar sobre el modo en que existimos, en cómo estar en el mundo habitando, todo pensar en este sentido no es que sea pertinente sino que es necesario. Además, hay otra cuestión que podríamos tener en cuenta tras la lectura atenta de Pensar, Habitar, Construir y es ese carácter del habitar humano vinculado a la tierra y al cuidado de ella, que hoy nos interesaría destacar, no tanto como ese campo que hay que labrar y cultivar, sino como el cuidar de una Tierra que siendo nuestra casa, nos hemos olvidado de proteger, poniéndola continuamente en peligro.

En todo caso la discusión en torno a las necesidades de un ser humano cuya esencia constitutiva es el habitar, el vivir ligado a lo físico y a lo humano (tierra, cielo, mortales y divino en lenguaje de Heidegger), con su carácter de transitoriedad, buscando la permanencia, nos puede conducir a plantear, por encima de la tristeza que nos produce en muchas ocasiones contemplar y vivir en algunas de nuestras ciudades y en nuestro mundo, cómo deberían ser los lugares que habitamos para que fueran realmente lugares habitables. Al menos como fin a conseguir, la propuesta heideggeriana de pensar en el construir y por tanto en el habitar sigue siendo pertinente, aunque solo suponga un pequeño matiz si lo comparamos con los auténticos problemas de habitabilidad que nuestro mundo tiene planteados en el siglo XXI.

Nieves Muñoz Profesora de Filosofía 
